\title{
MODELLING AND VIBRATION ANALYSIS OF A ROAD PROFILE MEASURING SYSTEM
}

\author{
C. B. Patel ${ }^{1}$, P. P. Gohil ${ }^{1}$ and B. Borhade ${ }^{2}$ \\ ${ }^{1}$ Department of Mechanical Engineering \\ Charotar Institute of Technology (Faculty of Technology and Engineering) \\ Charotar University of Science and Technology, Changa, Anand-388 421, India \\ Phone: +919375435955 \\ E-mail: cbchirag@gmail.com, piyushgohil.me@ecchanga.ac.in \\ ${ }^{2}$ Mahindra Navistar Automotive Limited, Pune, India.
}

\begin{abstract}
During a vehicle development program, load data representing severe customer usage is required. The dilemma faced by a design engineer during the design process is that during the initial stage, only predicted loads estimated from historical targets are available, whereas the actual loads are available only at the fag end of the process. At the same time, changes required, if any, are easier and inexpensive during the initial stages of the design process whereas they are extremely costly in the latter stages of the process. The use of road profiles and vehicle models to predict the load acting on the whole vehicle is currently being researched. This work hinges on the ability to accurately measure road profiles. The objective of the work is to develop an algorithm, using MATLAB Simulink software, to convert the input signals into measured road profile. The algorithm is checked by the MATLAB Simulink 4 degrees of freedom half car model. To make the whole Simulink model more realistic, accelerometer and laser sensor properties are introduced. The present work contains the simulation of the mentioned algorithm with a half car model and studies the results in distance, time, and the frequency domain.
\end{abstract}

Keywords: road profile measurement, half car model, 4 degrees of freedom model, vehicle vibration, vehicle dynamic modelling.

\section{INTRODUCTION}

The product development exercise in the automobile industry can be finished after doing durability calculations. The durability test is known as the life cycle test and is essentially for testing the reliability of vehicles. This test offers important data to determine the life cycle of vehicles; through the analysis of cost vs. effect, this test data is used for evaluating and predicting defects of the main parts of the vehicle during the life cycle. One of the important test factors in the endurance test is the vibration environments in which the vehicles are operated. The environment affects the reliability of vehicles owing to fatigue. Therefore, the measurement of road profile and the evaluation of profile characteristics are important points to get reliable endurance test results (Connon, 2000; Dodds and Robson, 1973; Min and Jeong, 1994). At the beginning of the vehicle development program it is a must to possess load data that represents severe customer usage. These target loads are used in the design process to ensure that the vehicle components are sufficiently strong. The actual load in 
components can only be measured once a prototype is available. However, this is at the very end of the development program (Perera and Kohn, 2002). The dilemma faced by a design engineer during the design process is that during the initial stages only predicted loads estimated from historical targets are available, whereas the actual loads are available only at the fag end of the process. At the same time, changes required, if any, are easier and inexpensive during the initial stages of the design process, whereas they are extremely costly in the latter stage of the process. It is advantageous, therefore, to accurately predict the target vehicle loads at an early stage in the design program (Pawar and Saraf, 2009).

Prediction of the target loads at the start of the vehicle development program can only be achieved by doing virtual testing of the vehicle. Basic requirements for the virtual testing of the vehicle are to have vehicle model and accurate road profile data in multi body dynamic (MBD) software. But a CAD model can only be ready after doing the design calculations, and further design can start after having the load data. So, a basic requirement is to have road profile data first, before developing the road profile measuring system (RPMS) needed to develop an algorithm and validate it with mathematical multi degrees of freedom vehicle models. The emphasis of this paper is on the development of an algorithm for a road profile measuring system and its validation with a linear $4 \mathrm{DOF}$ vehicle dynamic model. It is recommended that the algorithm should be validated with more and more degrees of freedom, like having an actual vehicle. It can be said that a RPMS is accurate when it is free from different types of error and errors introduced because of the road surface (water, creaks, etc.) and the speed of the vehicle (tyre leaves of the ground); to remove all kinds of errors, the amount of filtration needs to be increased.

Road surface events are the same for all kinds of vehicles and components, only the vehicle responses vary. In this way, the road profiles are independent of the vehicle and have widespread application. Figure 1 shows a small patch of road surface with longitudinal and lateral profiles. The longitudinal profile provides the pitching effect to the vehicle and the lateral profile is responsible for the rolling effect.

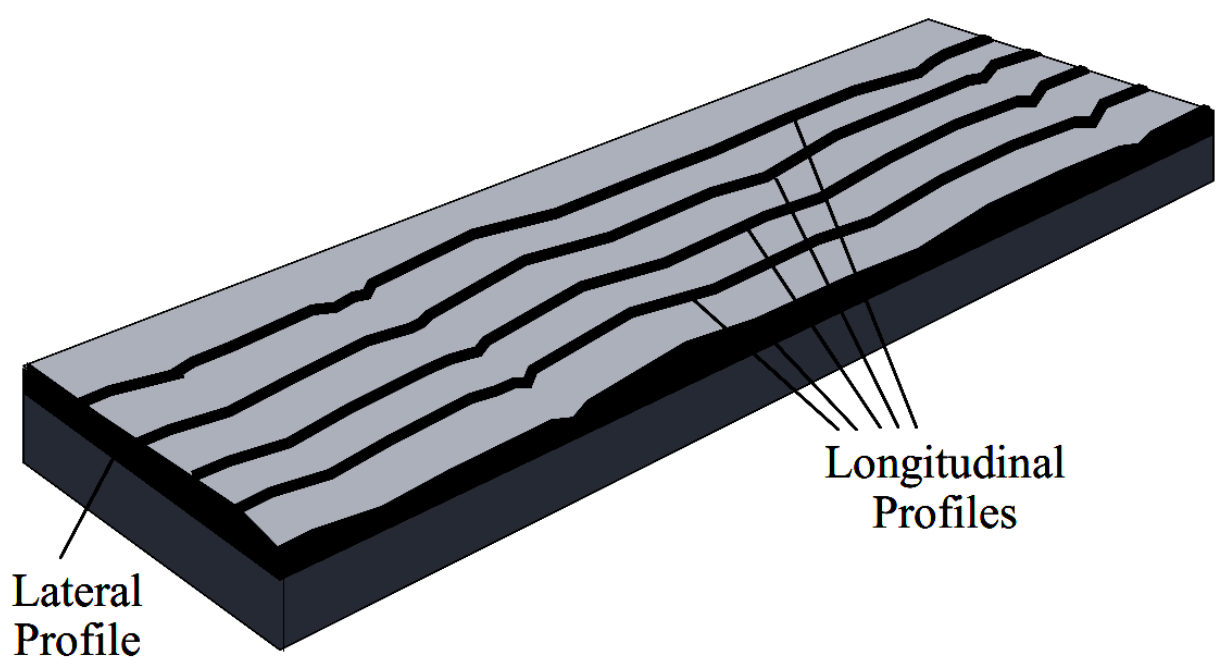

Figure 1: Longitudinal surface profiling (Michael and Steven, 1998)

Using road profiles in the design process can greatly improve the the component development process. Target roads that represent the road input can be defined which a 
real vehicle might experience, when driven by a customer (Min and Jeong, 1994). These target roads can then be used with multi-body simulation software to predict wheel loads early in the design process. Component loads then can be predicted, providing reliable input for finite element analysis, design optimization and lab testing. The pavement profile measurement exercise has continued for last 50 years, as per work done by General Motors (Saeger and Ferris, 2003) to develop a high speed profiler (inertial profiler) which is attached as a fifth wheel to the vehicle body. The objective is to measure the road profile at highway speeds with the help of accelerometers coupled with laser sensors. (ASTM, 1996). The road damage assessment methodology utilizes an artificial neural network that reconstructs road surface profiles from measured vehicle accelerations. The results show that the road profiles and associated defects can be reconstructed to within a $20 \%$ error at a minimum correlation value of $94 \%$. (Ngwangwa et al., 2009). Vehicles out rigged with inertial profilers. This type of inertial measurement provides a sort of filtered roadway profile. The currently available systems in the market are not suitable (Pawar and Saraf, 2009) for measurement of severely damaged pavement, test track profiles, or off-road surfaces. Researchers at Mitsubishi (Patel, 2009) were able to use a series of four collinear lasers extending along the length of the vehicle to determine the road profile.

There are many methods reported in the literature for obtaining road profiles by direct measurement of the road itself (Ngwangwa et al., 2008). However, (Gonzalez et al., 2007) despite major improvements in recent years in the quality of road-profiling equipment, these devices remain generally expensive to purchase, their use with time is inefficient and their operation specialized. They demonstrate numerically the applicability of vehicle acceleration measurements on the body. Measured results are influenced by the properties of the vehicle's mechanical system and measuring speed in response type road roughness measuring system (Michael and Steven, 1998). A high speed profiler is used to measure the road profile at highway speed but data can be collected at every $1.88 \mathrm{~cm}$ distance (AE, 2009). A profilograph is an accurate data collection measuring system, but the speed must be slow (SSI, 2009). The individual height measures must be accurate to $0.5 \mathrm{~mm}$ or less. But this process will take too much time to measure the road profile. Also Dipstick (FCT, 2009) measures the data very accurately, but at very slow speed because we have to walk with that. The object of this invention is to provide a method and system of the described type which provides a road profile output which is determined from information that is independent of the motion of the sprung mass of the measurement vehicle. A more specific object is to provide a road profile measurement system which does not rely on the independent measurement of the surface of the roadway, but only on the interaction of the vehicle's supporting tire with the road surface, thereby allowing the system to obtain a measurement of any surface over which the measurement vehicle can be driven. This allows the determination of the profile of off-road terrain. A further object of this invention is to provide a method and apparatus for the measurement of the road surface profile in which the introduction of computational error is minimized by performing data manipulation in the frequency domain and in the time domain.

\section{CONCEPT}

An algorithm is to be developed to measure the road profile, which contains different types of filters to filter the unwanted frequencies and noise. Later validation of the algorithm is obligatory with more degrees of freedom for the dynamic vehicle model. 
Figure 2 shows the simple working concept of a road profile measuring system. A mathematical model of the vehicle, with its various degrees of freedom and nonlinearity, can become extremely complex. A model for measuring an accurate road profile can be achieved, however by using a half car model that contains three masses, four springs and four dampers (Figure 3.). In this case, the half car model represents the whole front and rear of the vehicle, but reduces it to two wheel masses and the body mass. The objective of the half car model is to simulate the vehicle being excited by the input road profile and comparing the input profile with the measured profile at different speeds. If both input and measured profile have the same nature and amplitude at different speeds, then we can say the measured profile can be used for MBD simulation. However, in actual practice both input and measured profile cannot be the same naturewise and amplitudewise also. Because each measuring device has its own error, $100 \%$ agreement between input and measured profile is not possible practically.

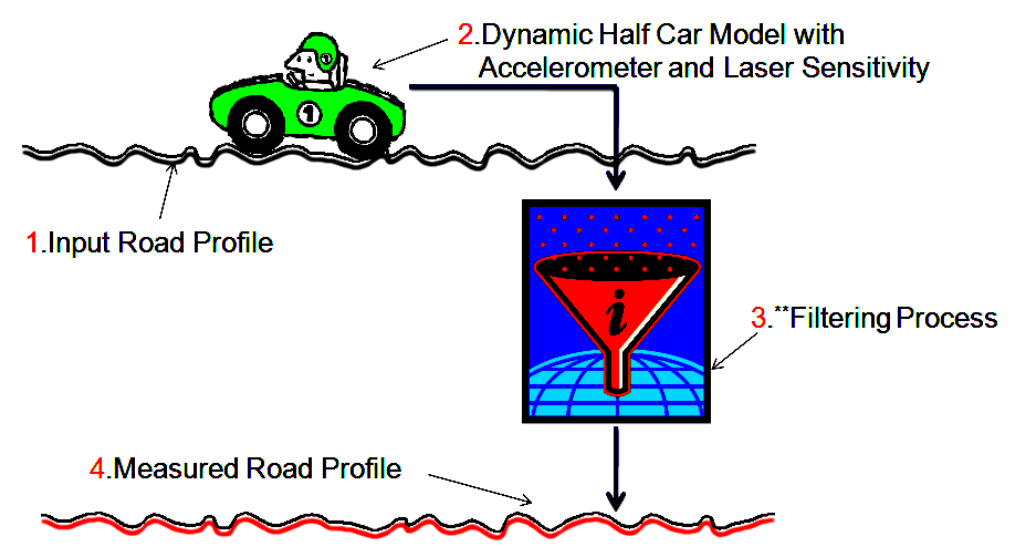

Figure 2: Working of road profile measuring system

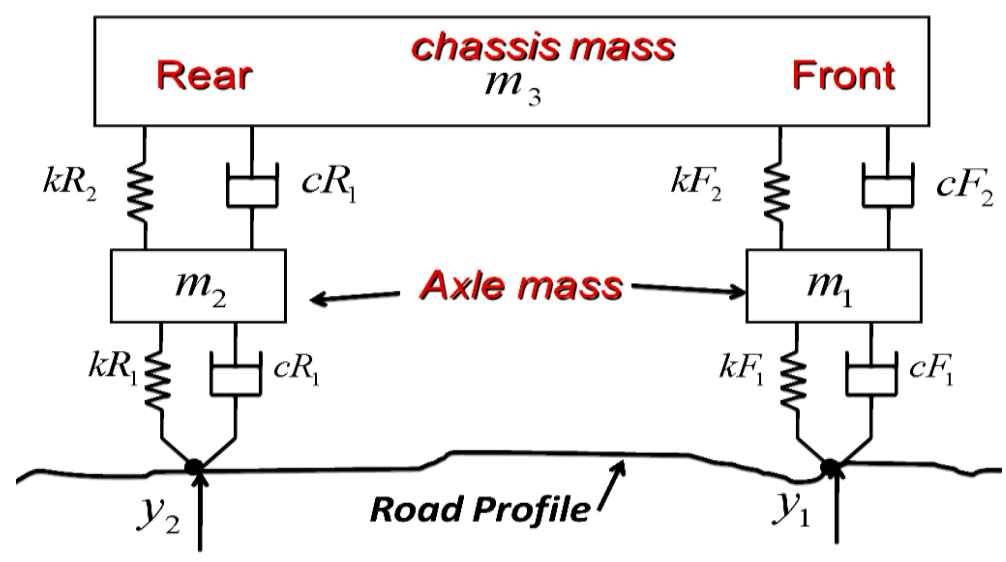

Figure 3: Dynamic model (Half car) of vehicle

The measured profile needs to be compared with the input profile to validate the road profile measuring system. A road profile measuring system having absolute error (i.e. measured profile-input profile) up to $2 \mathrm{~mm}$ at different speeds in different conditions is said to be acceptable, especially for HMV application (Mahindra Navistar Automotive Limited, Pune), i.e. the measured road profile can be use for MBD simulation of the vehicle. 


\section{MATHEMATICAL MODELLING AND VALIDATION}

A 4 degree of freedom (DOF) mathematical model of a complete vehicle was developed and used to obtain the measured road profile. The coordinate system was defined as follows:

- Positive $\mathrm{x}$-axis pointing to the front of the vehicle.

- Positive y-axis pointing to the driver's left.

- Positive $\mathrm{z}$-axis pointing up.

- Positive angles are defined by the right-hand rule.

As discussed above, the original vehicle contains so many nonlinear systems. Simulation of the full physical vehicle is difficult; hence, it is converted to a half car dynamic model. Suspension and tyres are considered as a spring and damper system. The front axle and rear axle are considered as single masses as shown in Figure 3, and the chassis with body mass is considered as a single mass lying on both front and rear suspension. As shown in Figure 3, the dynamic half car model represents the vehicle. The dynamic model is considered to be a spring mass and damper system. The dynamic model is considered to be a spring mass and damper system possessed of pitch and bounce motion for the chassis mass, where, $y_{1}$ and $y_{2}$ are the road inputs for the front and rear, respectively.

- Both front and rear axle have bouncing motion.

- Both tyres and suspensions are represented with spring and damping effect.

- Both front and rear axle are represented by single masses.

- Random road profile is considered as road input.

- Pitching and bouncing motion is considered at the C.G. of the chassis mass.

The free body diagram shows the different kind of forces acting on the body mass, front, and rear axle masses. The bouncing motion of the masses is considered in the ' $z$ ' direction, and pitching motion is considered in the ' $z x$ ' plane about the ' $y$ ' direction. For this model, the upward and anticlockwise direction is considered as positive. Figure 4 shows the free body diagrams for mass $m_{3}$ (chassis mass), mass $m_{1}$ (front axle mass) and mass $m_{2}$ (rear axle mass) of the half car system. The dynamic equations of motion are developed from the free body diagrams (Figure 4) as follows.

$$
\begin{aligned}
& m_{1} \ddot{x}_{1}=c F_{2}\left(\dot{x}_{3}-\dot{x}_{1}+a \dot{\theta}\right)+k F_{2}\left(x_{3}-x_{1}+a \theta\right)-k F_{1}\left(x_{1}-y_{1}\right)-c F_{1}\left(\dot{x}_{1}-\dot{y}_{1}\right) \\
& m_{2} \ddot{x}_{2}=c R_{2}\left(\dot{x}_{3}-\dot{x}_{2}-b \dot{\theta}\right)+k R_{2}\left(x_{3}-x_{2}-b \theta\right)-k R_{1}\left(x_{2}-y_{2}\right)-c R_{1}\left(\dot{x}_{2}-\dot{y}_{2}\right) \\
& m_{3} \ddot{x}_{3}=-\left[k R_{2}\left(x_{3}-x_{2}-b \theta\right)+c R_{2}\left(\dot{x}_{3}-\dot{x}_{2}-b \dot{\theta}\right)+k F_{2}\left(x_{3}-x_{1}+a \theta\right)+c F_{2}\left(\dot{x}_{3}-\dot{x}_{1}+a \dot{\theta}\right)\right] \\
& I \ddot{\theta}=k R_{2}\left(x_{3}-x_{2}-b \theta\right)+c R_{2}\left(\dot{x}_{3}-\dot{x}_{2}-b \dot{\theta}\right)-k F_{2}\left(x_{3}-x_{1}+a \theta\right)-c F_{2}\left(\dot{x}_{3}-\dot{x}_{1}+a \dot{\theta}\right)
\end{aligned}
$$




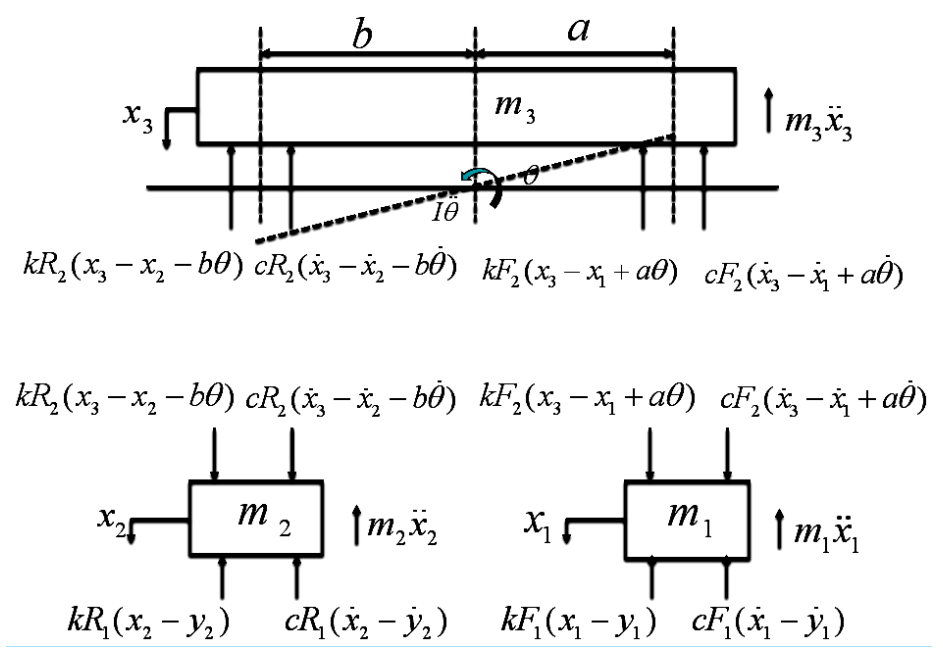

Figure 4: Free body diagram of half car model

Eqs 1 to 4 can be represented in matrix form:

$$
\begin{aligned}
& {\left[\begin{array}{cccc}
m_{1} & 0 & 0 & 0 \\
0 & m_{2} & 0 & 0 \\
0 & 0 & m_{3} & 0 \\
0 & 0 & 0 & I
\end{array}\right]\left\{\begin{array}{c}
\ddot{x}_{1} \\
\ddot{x}_{2} \\
\ddot{x}_{3} \\
\ddot{\theta}
\end{array}\right\}+\left[\begin{array}{cccc}
k F_{1}+k F_{2} & 0 & -k F_{2} & -a k F_{2} \\
0 & k R_{1}+k R_{2} & -k R_{2} & b k R_{2} \\
-k F_{2} & -k R_{2} & k R_{2}+k F_{2} & a k F_{2}-b k R_{2} \\
-k F_{2} & k R_{2} & k F_{2}-k R_{2} & a k F_{2}+b k R_{2}
\end{array}\right]\left\{\begin{array}{c}
x_{1} \\
x_{2} \\
x_{3} \\
\theta
\end{array}\right\}} \\
& +\left[\begin{array}{cccc}
c F_{1}+c F_{2} & 0 & -c F_{2} & -a c F_{2} \\
0 & c R_{1}+c R_{2} & -c R_{2} & b c R_{2} \\
-c F_{2} & -c R_{2} & c F_{2}+c R_{2} & a c F_{2}-b c R_{2} \\
-c F_{2} & c R_{2} & c F_{2}-c R_{2} & a c F_{2}+b c R_{2}
\end{array}\right]\left\{\begin{array}{c}
\dot{x}_{1} \\
\dot{x}_{2} \\
\dot{x}_{3} \\
\dot{\theta}
\end{array}\right\}=\left\{\begin{array}{c}
k F_{1} y_{1}+c F_{1} \dot{y}_{1} \\
k R_{1} Y_{2}+c R_{1} \dot{y}_{2} \\
0 \\
0
\end{array}\right\}
\end{aligned}
$$

Eq. 5 can be represented as Eq. 6 as follows:

$$
[m]\{\ddot{U}\}+[c]\{\dot{U}\}+[k]\{U\}=\{F\}
$$

In Eq. 6, the mass, stiffness, damping and force matrix are known and the acceleration, velocity and displacement matrix are unknown. It is not possible to solve all those equations by a simple analytical method. It is now possible to assemble the equations of motion for the behavior of individual components of a vehicle into a comprehensive model of the overall vehicle. This allows simulation using Runge-Kutta or other solvers and evaluation of its behavior before such vehicles are actually constructed. Such models can evaluate performance measures that could not be addressed in simulation in the past and is used extensively in analysing the dynamics of multi body systems. The first requirement is to validate those equations which are derived from the half car model. 


\section{VALIDATION}

In simulation, to measure the road profile, the first step is to develop the Simulink model for 4 DOF and validate it with 5 DOF and 10 DOF models. Two research papers (Gawade et al., 2004; Paulo et al., 2001) have been taken for validating the results obtained from the model developed in the present work.

- Wheel Lift-off and Ride Comfort study of Three-wheeled Vehicle over Bump: 5 DOF (Gawade et al., 2004)

- A Numerical Model for Passenger Car Ride Comfort Studies: 10 DOF (Paulo et al., 2001)

Mass, stiffness and damping properties are taken to be the same as those used for the research papers. The comparison in Figure 5 clearly shows that there is $100 \%$ agreement for the vertical acceleration at the half sine wave bump profile. Simulation has been done for the 4 DOF model with consideration of the tyre damping effect. The same graph can be plotted for the 4 DOF model with consideration of the tyre damping effect in Figure 6. The maximum negative acceleration pulse of duration $0.12 \mathrm{~s}$ starts at $0.49 \mathrm{~s}$ and has a minimum value of $9.495 \mathrm{~m} / \mathrm{s}^{2}$. Figure 6 shows a reduction in acceleration because of the tyre damping effect. Hence, it is proved that the derived equations for the 4 DOF model are more accurate. For validation of the 4 DOF model, only a metallic obstacle path (Paulo et al., 2001) is considered as input and a step time of $0.004 \mathrm{sec}$ has been taken. As the half car model is considered, only one side (left or right) front and rear wheel acceleration can get obtained. Figure $7(\mathrm{a}-\mathrm{b})$ is considered for the validation as front left and rear left wheel acceleration respectively for the 10 DOF model. Figure $7(\mathrm{c}-\mathrm{d})$ represents the wheel acceleration for front and rear wheel respectively for the 4 DOF model.

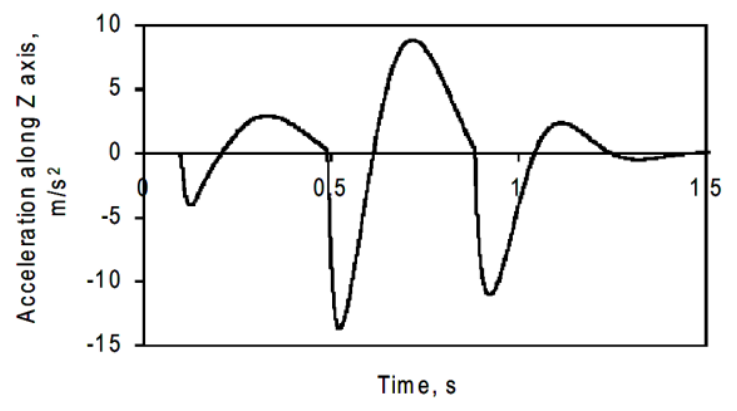

(a) $5 \mathrm{DOF}$

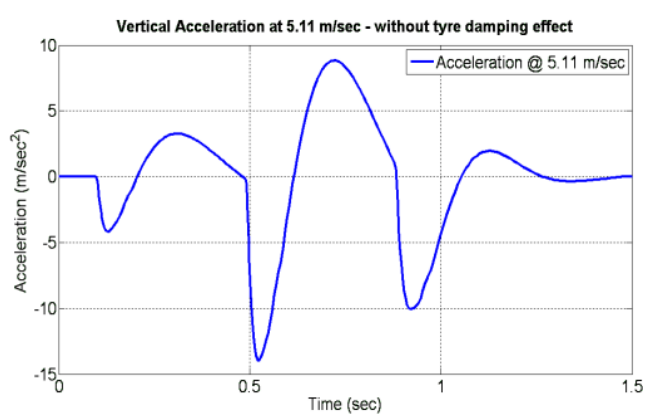

(b) $4 \mathrm{DOF}$

Figure 5: Vertical acceleration half sine wave bump profile

The reasons for the dissimilarity in paper results and the 4 DOF model are as shown in Table 1 . The paper model is a 10 DOF full car model and the present work model is considered with $4 \mathrm{DOF}$ as half car model. The paper model consists of a suspension system in three different damping phases as the work is concerned with ride comfort. The present work is concerned with the measurement of the road profile, so, the suspension system is considered as one phase damping. The fixed length of contact tyre model is considered for ride comfort analysis and the point contact tyre model is considered for road profile measurement. 


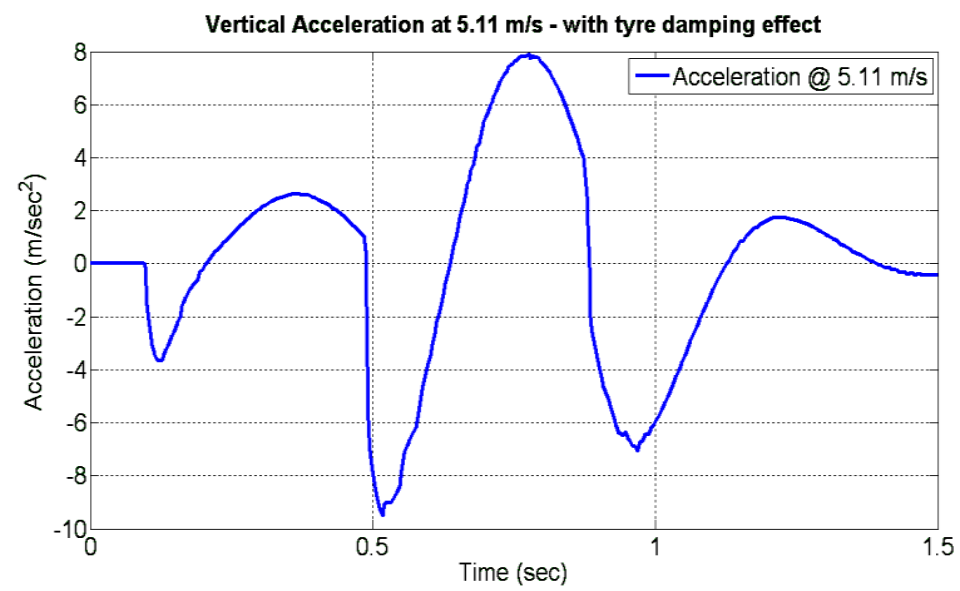

Figure 6: Vertical acceleration half sine wave bump profile (with tyre damping) [4DOF]

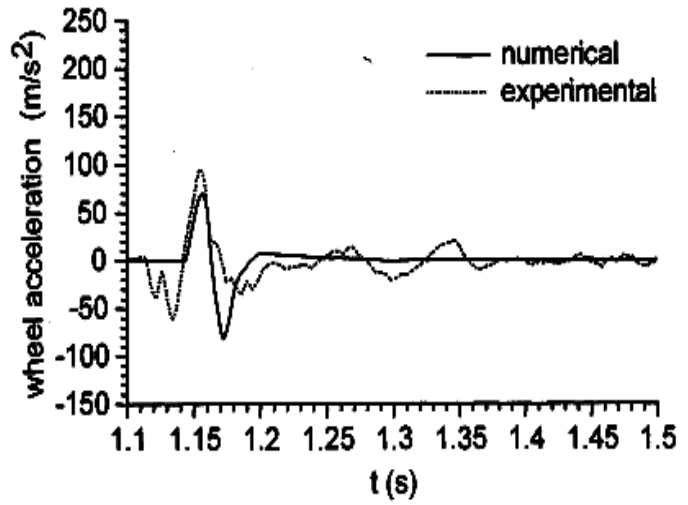

(a) Front left wheel

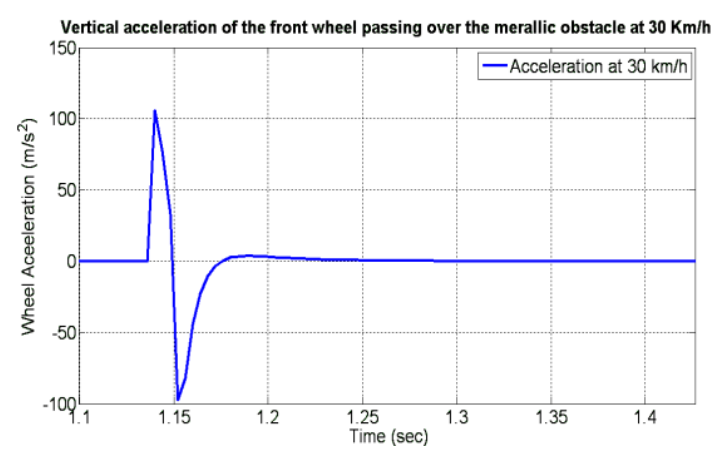

(c ) Front left wheel (4 DOF)

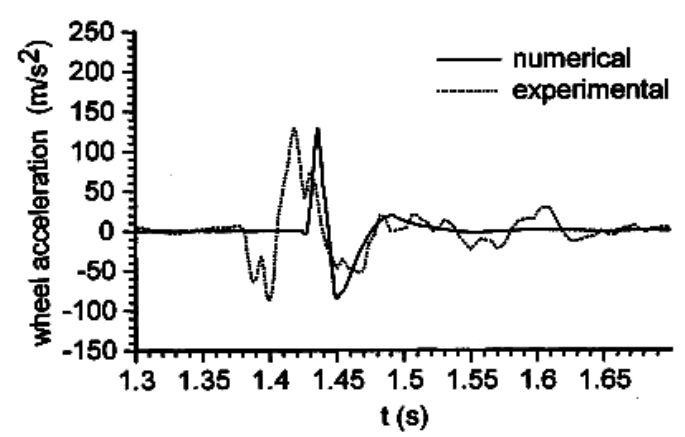

(b) Rear left wheel

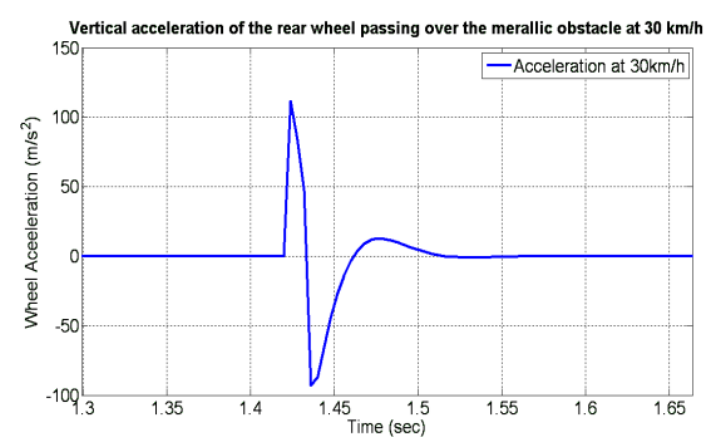

(d) Real left wheel (4 DOF)

Figure 7: Vertical acceleration of wheel passing over the metallic obstacle at $30 \mathrm{~km} / \mathrm{h}$.

The results of both papers (Gawade et al., 2004; Paulo et al., 2001) match with the new 4 DOF model results. Hence, the new MATLAB/Simulink 4 DOF model is validated. So, the new 4 DOF model can be used for further simulation of road profile measuring systems. 
Table 1: Assumptions for 10 DOF and 4 DOF models

\begin{tabular}{ll}
\hline \multicolumn{1}{c}{ 10 DOF (Paulo et al., 2001) } & \multicolumn{1}{c}{ 4DOF } \\
\hline Fixed length of contact tyre model & Point contact tyre model \\
Suspension with three phase damping & Suspension with one phase damping \\
Full car model & Half car model \\
\hline
\end{tabular}

\section{HALF CAR MODEL SIMULATION}

A half car vehicle dynamic MATLAB-Simulink model (4DOF) is developed to validate the developed algorithm. The 4 DOF model is developed under the considerations mentioned in Table 2. In the model, accelerometer error (three types) and laser sensitivity are introduced to make the model related to practical approaches. For the simulation, a random road profile is selected as the input road profile. A MATLABSimulink model is developed, using the derived, linear equations of motion of the half car vehicle. Simulation is done for different speeds to check whether the developed algorithm model is speed independent within tolerance, because in actual conditions, the speed of the vehicle will continuously vary with time or distance. The system should also vehicle independent. For the simulation a 25 meter road patch is selected, so the simulation time is different for each speed because the MATLAB-Simulink model is time dependent. The algorithm itself arranges for the sample time to collect the data after every $1 \mathrm{~cm}$, no matter which speed.

Output of the model is plotted in the time and frequency domains. Sometimes using only one domain is not adequate to predict the measured road profile at different speeds. It may happen that the measured road profile matches the input road profile in distance and the time domain, but it may happen that the input and measured road profile have different frequencies. So, such profiles work as different profiles at different speeds, that's why such profiles cannot used in the MBD software for the further simulation like prediction of the vehicle endurance from the input road profile etc.

\section{Half car model properties}

The half car model properties used for the simulation are shown in Table 3. The model properties may differ if the vehicle is changed. However, the results should not change. Figure 8 shows the half car Simulink model. Simulation is to be done for different speeds, to check the independence of the model from vehicle speed at the specified tolerance limit. 
Table 2: 4 DOF Model considerations

\begin{tabular}{|c|c|}
\hline Parameter & Description \\
\hline Type of Model & Half car vehicle dynamic model \\
\hline \multirow[t]{4}{*}{ Degree of freedom } & $4 \mathrm{DOF}$ \\
\hline & - 1 DOF (bouncing +/- Z direction) \\
\hline & - 1 DOF (bouncing $+/-\mathrm{Z}$ direction) \\
\hline & $\begin{aligned} \text { Frame (body) - } & 2 \mathrm{DOF} \text { (bouncing }+/-\mathrm{Z} \text { direction, } \\
& \text { Pitching moment about y direction) }\end{aligned}$ \\
\hline Tyre & Point contact model with spring and damping effect \\
\hline Input Road Profile & Random road profile (Paulo et al., 2001) \\
\hline Suspension & Spring and damping effect \\
\hline \multirow[t]{4}{*}{ Accelerometer } & Model 2220 (SD, 2009) \\
\hline & Sensitivity $: 2 \%$ \\
\hline & Bias error \\
\hline & Random error : $0.1 \%$ \\
\hline Laser & Sensitivity $\quad: 3 \%$ (Approx.) \\
\hline Software used & MATLAB 7.3 and SIMULINK \\
\hline Solver & ODE 4 (Runge-Kutta) \\
\hline Sample Time & Speed dependent (Keeping $1 \mathrm{~cm}$ distance constant) \\
\hline Length of Road Patch & $25 \mathrm{~m}$ \\
\hline \multirow[t]{3}{*}{ Speed for simulation } & $30 \mathrm{~km} / \mathrm{h} \quad(3 \mathrm{sec})$ \\
\hline & $60 \mathrm{~km} / \mathrm{h} \quad(1.5 \mathrm{sec})$ \\
\hline & 100 km/h $(0.9 \mathrm{sec})$ \\
\hline Output & Time and frequency domain \\
\hline
\end{tabular}

Table 3: List of 4 DOF half car model properties (Paulo et al., 2001)

\begin{tabular}{|c|c|c|c|}
\hline \multicolumn{2}{|r|}{ Parameter } & Value & Unit \\
\hline \multicolumn{4}{|c|}{ Tyre } \\
\hline$k F_{1}$ & Front wheel stiffness & 134000 & $\mathrm{~N} / \mathrm{m}$ \\
\hline$c F_{1}$ & Front wheel damping & 700 & $\mathrm{~N}-\mathrm{sec} / \mathrm{m}$ \\
\hline$k R_{l}$ & Rear wheel stiffness & 134000 & $\mathrm{~N} / \mathrm{m}$ \\
\hline$c R_{I}$ & Rear wheel damping & 700 & $\mathrm{~N}-\mathrm{sec} / \mathrm{m}$ \\
\hline \multicolumn{4}{|c|}{ Front axle } \\
\hline$m_{1}$ & Front unsprung mass (wheel, axle) & 62.2 & $\mathrm{~kg}$ \\
\hline$x_{1}$ & Front unsprung mass displacement & Output & $\mathrm{m}$ \\
\hline \multicolumn{4}{|c|}{ Rear axle } \\
\hline$m_{2}$ & Rear unsprung mass (wheel, axle) & 60 & $\mathrm{~kg}$ \\
\hline$x_{2}$ & Rear unsprung mass displacement & Output & $\mathrm{M}$ \\
\hline \multicolumn{4}{|c|}{ Body } \\
\hline$m_{3}$ & Sprung mass (chassis) & 1200 & $\mathrm{~kg}$ \\
\hline & Sprung mass displacement & Output & $\mathrm{m}$ \\
\hline$k F_{2}$ & Front suspension stiffness & 28000 & $\mathrm{~N} / \mathrm{m}$ \\
\hline$c F_{2}$ & Front suspension damping & 2500 & $\mathrm{~N}-\mathrm{sec} / \mathrm{m}$ \\
\hline$k R_{2}$ & Rear suspension stiffness & 21000 & $\mathrm{~N} / \mathrm{m}$ \\
\hline$c R_{2}$ & Rear suspension damping & 2000 & $\mathrm{~N}-\mathrm{sec} / \mathrm{m}$ \\
\hline$a$ & Centre line distance between front wheel and C.G. & 0.847 & $\mathrm{~m}$ \\
\hline$b$ & Centre line distance between rear wheel and C.G. & 1.513 & $\mathrm{~m}$ \\
\hline$I$ & Moment of inertia of sprung mass & 2100 & $\mathrm{Kg}-\mathrm{m}^{2}$ \\
\hline$\theta$ & Pitch angle & Output & degree \\
\hline
\end{tabular}




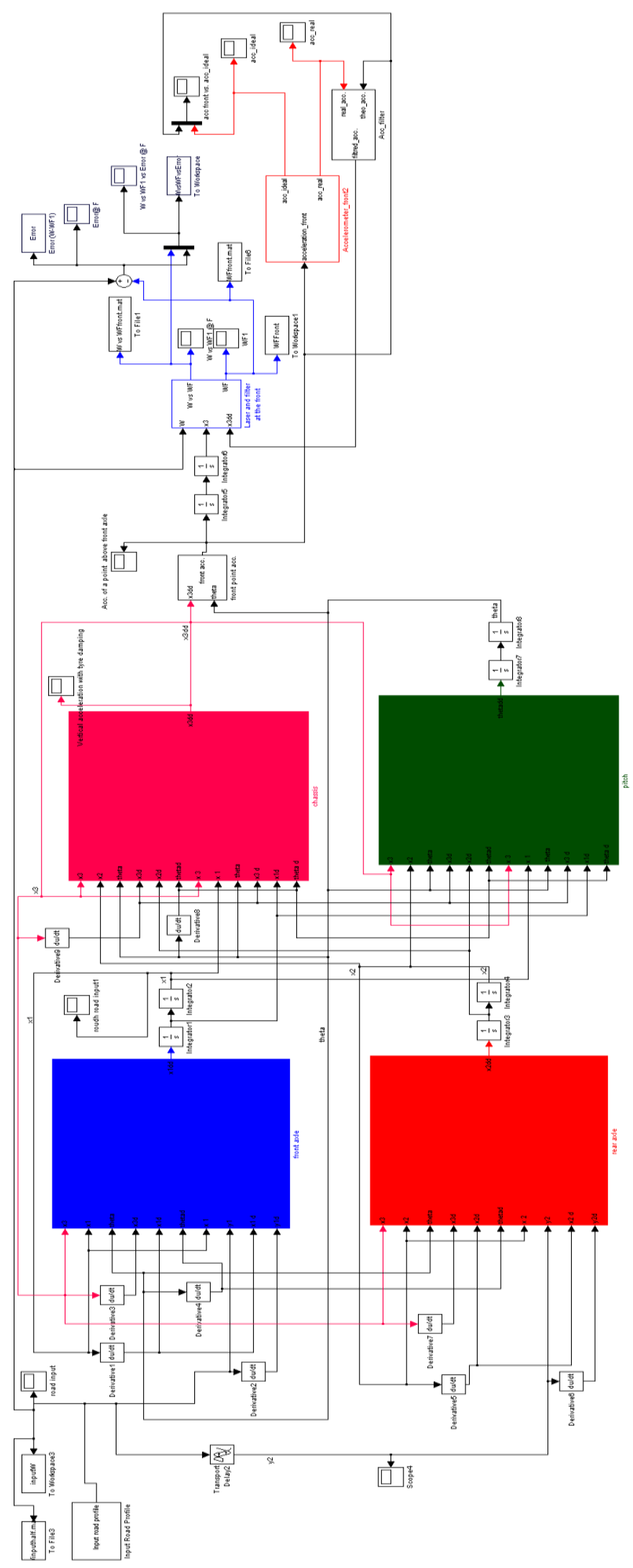

Figure 8: Simulink block diagram of 4 DOF Half car model 


\section{RESULTS AND DISCUSSION}

\section{Input road profile}

The input road profile is selected from the MIRA (Paulo et al., 2001) model. The selected profile is the random type; the same as the actual profile. The PSD of the selected profile matches the measured road profile. The basic requirement for the input road profile is that the profile has to be same at each speed. All the data are collected considering different speeds of the vehicle. In simulation the speed of the vehicle is held constant. Figure 9 shows the input road profile in the lateral direction at different speeds. The road patch length is $25 \mathrm{~m}$. As mentioned above, the input road profile has to be the same at different speeds, but in this graph it is not seen to be the same. Figure 9(a) is in the time domain so on the $x$ axis it is compressed as the speed of the vehicle increases (i.e., as the time for travelling the $25 \mathrm{~m}$ of road patch is decreasing with increasing speed), and the amplitude of the graph is the same at any speed. This also can be proved by plotting the input road profile in the distance domain as shown in Figure 9 (b). The pink line is at $30 \mathrm{~km} / \mathrm{h}$, light green is at $60 \mathrm{~km} / \mathrm{h}$, and blue is at 100 $\mathrm{km} / \mathrm{h}$. The input road profile overlaps at different speeds of the vehicle, so only the blue line is visible. So, from that it is concluded that the input road profile is the same at the different speeds.

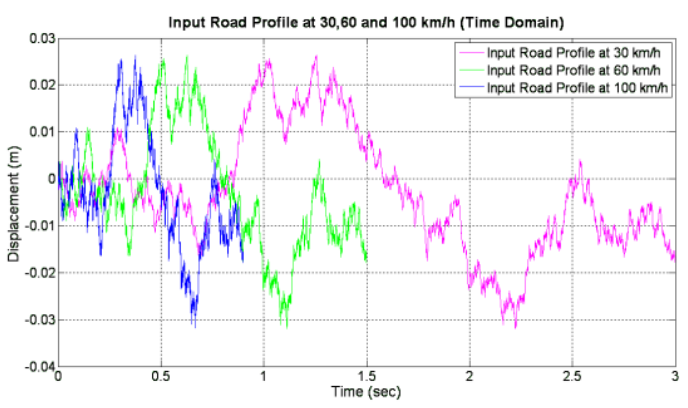

(a) Time domain

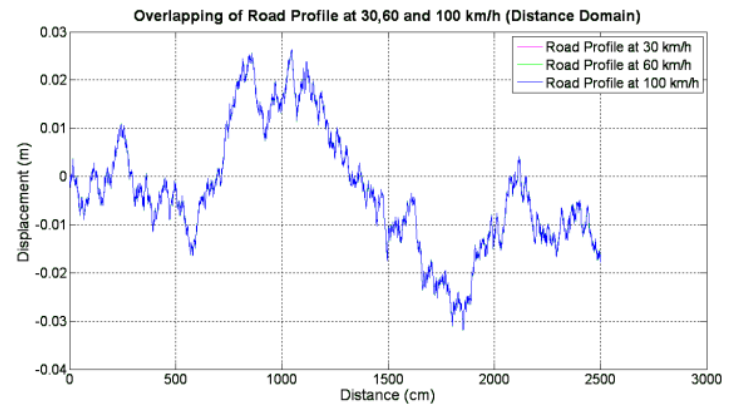

(b) Distance domain

Figure 9: Input road profile.

\section{Measured road profile}

The measured road profile is the processed output of the developed algorithm. Here a comparison has been done of the measured road profile with the input road profile to check the accuracy of the system. If any kind of discrepancy is found between the deliberate and the input road profile, it is called an error. Error is measured in unit of the meters or $\mathrm{mm}$. The error is plotted in the distance domain and in the frequency domain. The measured road profiles at the different speeds are elaborated as follows.

\section{Distance domain (error at 30, 60 and $100 \mathrm{~km} / \mathrm{h}$ )}

Figure 10 shows the comparison of errors at 30, 60, and $100 \mathrm{~km} / \mathrm{h}$. Table 4 shows the errors in displacement at different speeds of the vehicle. The discrepancies found at different speeds are very small and within the limit $(<1 \mathrm{~mm})$ in distance domain. It is concluded that the error increases by increasing the speed of the vehicle. 


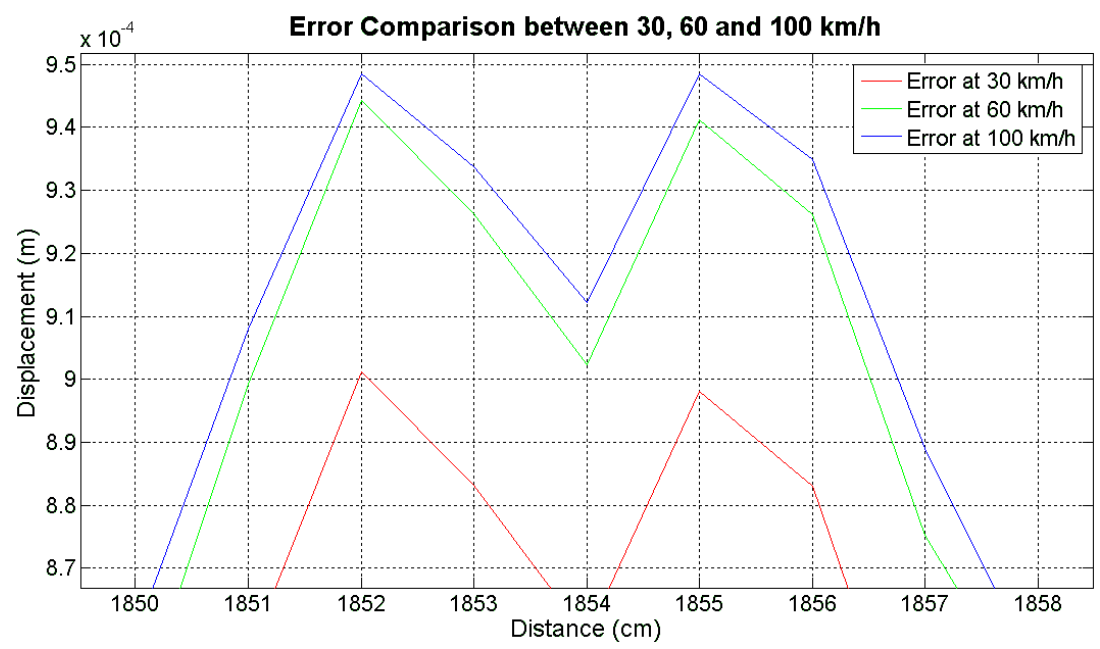

Figure 10: Error comparison (distance domain)

Table 4: Error comparison at different speeds of vehicle (distance domain)

\begin{tabular}{cccc}
\hline Speed of vehicle $\mathbf{( k m} / \mathbf{h})$ & Error $(\mathbf{m m})$ & Distance $(\mathbf{m})$ & Correlation (\%) \\
\hline 30 & 0.9012 & 18.52 & $97.175 \%$ \\
60 & 0.9443 & 18.52 & $97.039 \%$ \\
100 & 0.9484 & 18.52 & $97.027 \%$ \\
\hline
\end{tabular}

Frequency domain (error at 30, 60 and $100 \mathrm{~km} / \mathrm{h}$ )

Figure 11 shows the comparison of error in the frequency domain at different speeds $(30,60$ and $100 \mathrm{~km} / \mathrm{h})$ of the vehicle. Table 5 shows the errors in frequency at different speeds of the vehicle. The discrepancies found at different speeds are very small and within the limit $(<0.5 \mathrm{~mm})$ in the frequency domain. It is concluded that the error increases by increasing the speed of the vehicle. The speed is considered from $10 \mathrm{~km} / \mathrm{h}$ to $100 \mathrm{~km} / \mathrm{h}$ and the data is collected at each $10 \mathrm{~km} / \mathrm{h}$ speed: all the results are as shown in Figures 12 and 13. In Figure 12 it is clear that the error plot in $\mathrm{mm}$ is increasing with the speed of the vehicle. The difference in error from $10 \mathrm{~km} / \mathrm{h}$ to $20 \mathrm{~km} / \mathrm{h}$ is more than at 20 to $30 \mathrm{~km} / \mathrm{h}$ and the same thing is repeated up to $100 \mathrm{~km} / \mathrm{h}$. but after $70 \mathrm{~km} / \mathrm{h}$ the error line becomes approximately horizontally linear. Figure 13 shows the speed of vehicle vs agreement in percentage. The outcome of this graph is the agreement between input road profile and measured road profile. Figure 13 shows that the agreement between input and measured road profile is about $97.8 \%$ at the $10 \mathrm{~km} / \mathrm{h}$ and is reduced to $97.15 \%$ at $20 \mathrm{~km} / \mathrm{h}$. the difference in agreement between 10 and 20 is more than 30 and $40 \mathrm{~km} / \mathrm{h}$ and proceeding further, it becomes somewhat linear after $60 \mathrm{~km} / \mathrm{h}$. The agreement after $60 \mathrm{~km} / \mathrm{h}$ is above $97 \%$. Hence, after analysis of the results in the distance and frequency domains, it can be said that whatever discrepancies are found are because of the acceleration of the vehicle, which increases with the speed. On the other hand, it may be the solver error. 


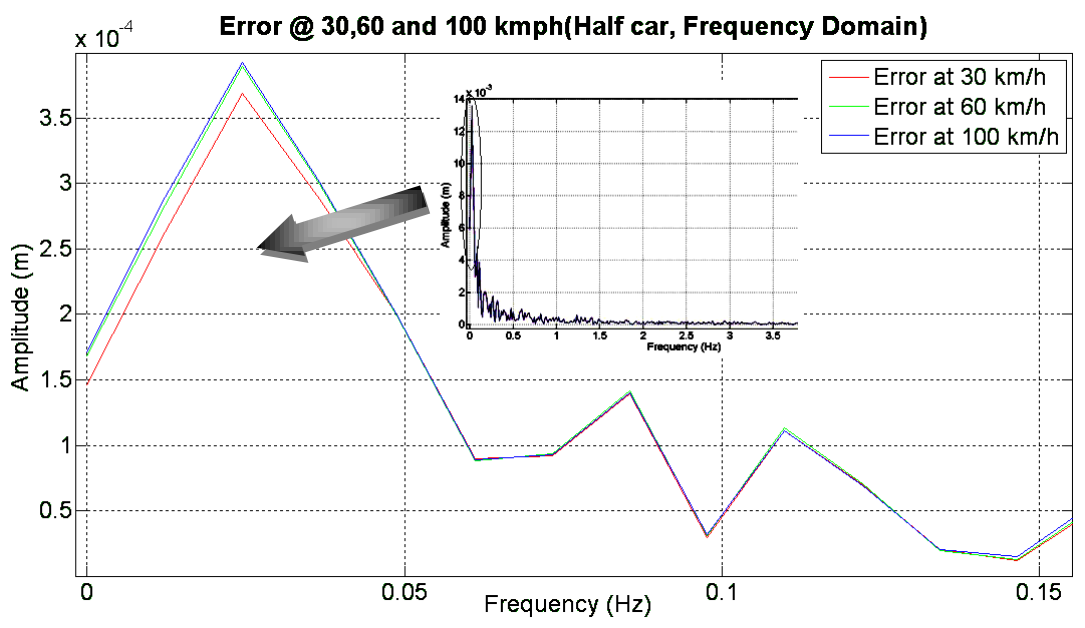

Figure 11: Error comparison (frequency domain)

Table 5: Error comparison at different speeds of vehicle (frequency domain)

\begin{tabular}{ccc}
\hline Speed of vehicle $\mathbf{( k m} / \mathbf{h})$ & Error $\mathbf{( m m})$ & Correlation $\mathbf{( \% )}$ \\
\hline 30 & 0.3684 & $97.18 \%$ \\
60 & 0.3891 & $97.05 \%$ \\
100 & 0.3923 & $97.03 \%$ \\
\hline
\end{tabular}

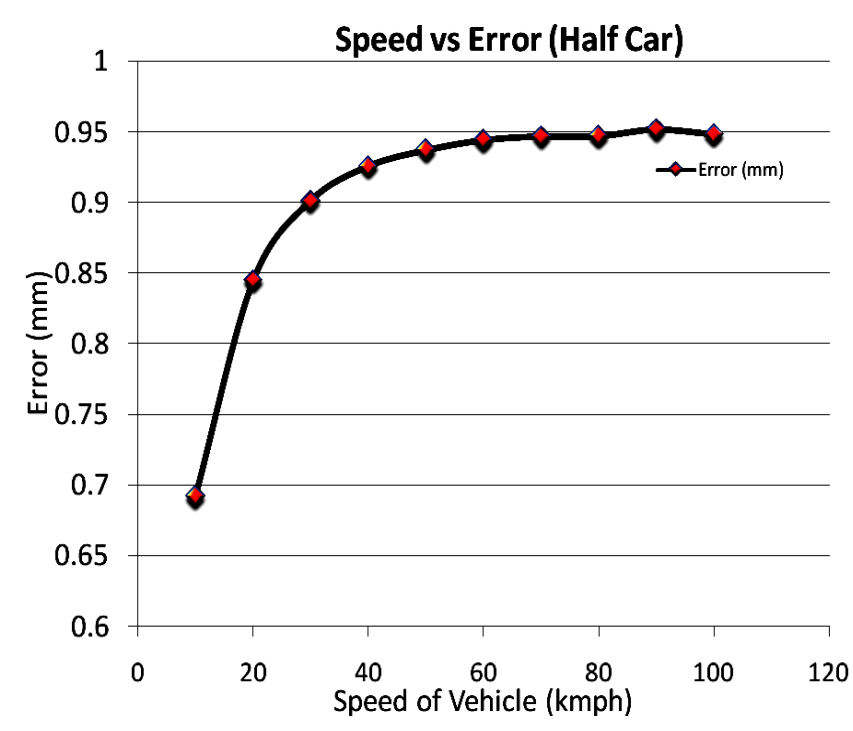

Figure 12: Speed of vehicle vs error 


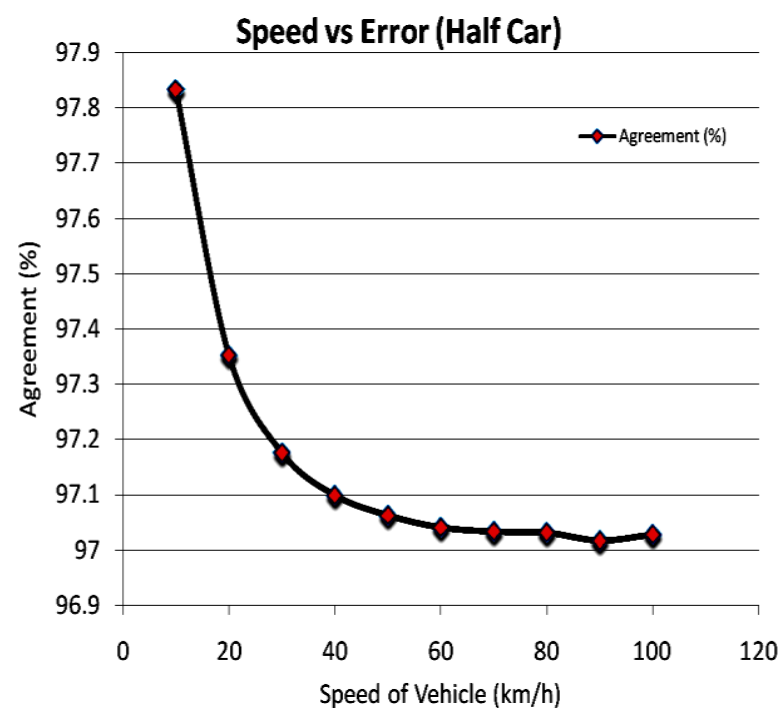

Figure 13: Speed of vehicle vs agreement

\section{CONCLUSION}

A complete half car model has been discussed for a road profile measuring system. The output of the model was elaborated in the time, distance and frequency domains in the preceding chapters. The maximum and minimum agreement of the measured road profile with the input road profile is $98 \%, 97 \%$, respectively. Hence the maximum accuracy of the road profile-measuring algorithm with the half car model is within 1 $\mathrm{mm}$, or, $96 \%$. After the simulation of a complete half car road profile measuring system, the outcome was a good agreement between input and output road profile. Here, the simulation done for the road profile measuring system considered only pitching and bouncing motion: rolling was not considered here. To validate the developed algorithm with more degrees of freedom, a linear dynamic vehicle model was developed in a 7 DOF full car model, considering roll, pitch and bounce motion for the chassis. Somehow, adequate results were not obtained at 60 and $70 \mathrm{~km} / \mathrm{h}$ speed. So the projected next step is to solve that dilemma with 7 DOF and validate the developed algorithm even with more degrees of freedom in a full car model. It is proposed to use the ADAMS full car model for supplementary validation because to create a full car model above 10 DOF becomes very convoluted with MATLAB.

\section{ACKNOWLEDGEMENTS}

We are thankful to the research paper review committee, Faculty of Technology and Engineering, CHARUSAT, H.O.D (Department of Mechanical Engineering) and Dr. Y. P. Kosta, Dean, Faculty of Technology and Engineering, Charotar University of Science and Technology, Changa for their guidance, encouragement and support in undertaking the present work. Special thanks to the management for their moral support and continual encouragement. 


\section{REFERENCES}

AE(Ames Engineering) (2009) http://www.amesengineering.com/amestxr.htm, accessed on 22-01-2009.

ASTM (1996) Standard Test Method for Measuring Longitudinal Profile of Traveled Surfaces with an Accelerometer Established Inertial Profiling Reference. Annual Book of ASTM standards Vol. 04.03. E950-96.

Connon, W.H. (2000) Determining vehicle sensitivity to changes in test - course roughness. IEST 46th Annual Technical Meeting and Exposition. pp 30-37.

Dodds, C.J. and Robson, J.D. (1973) The description of the road profile roughness. Journal of Sound and Vibration, 31, 175-183.

FCT (Face Construction Technologies, Inc.) 2009. http://www.prestostore.com/cgibin/pro16.pl?ref=dipstick\&pg=11398, accessed on 22-01-2009

Gawade, T.R., Mukherjee, S. and Mohan, D. (2004) Wheel lift-off and ride comfort of three-wheeled vehicle over bump. IE (I) Journal-MC, 85, 79-83.

Gonzalez, A., O'Brien, E.J., Li, Y.Y. and Cashell, K. (2007) The use of acceleration measurements to estimate road roughness. Vehicle System Dynamics, 46 (6), 483-499.

Michael, W.S. and Steven, M.K. (1996) The little book of profiling. University of Michigan, 2-5, 40, 41.

Min, B.H. and Jeong, W.U. (1994) Design method of test road profile for vehicle accelerated durability test. Journal of KSAE, 2 (1), 128-141.

Ngwangwa, H.M., Heyns, P.S., Labuschagne, F.J.J., Kululanga, G.K. (2009) Reconstruction of road defects and road roughness classification using vehicle responses with Artificial Neural Networks simulation. Journal of Terramechanics, 47 (2), 97-111.

Ngwangwa, H.M., Heyns, P.S., Labuschagne, K.F.J.J. and Kululanga, G.K. 2008. $27^{\text {th }}$ Southern African Transport Conference (SATC), pp. 312-319.

Patel, C.B. (2009) Modelling and vibration analysis of road profile measuring system. Masters Thesis, Gujarat University, India.

Paulo, C.G., de Barcellos, C.S. and da Rosa Neto, A. (2001) A Numerical Model for Passenger Car Ride Comfort Studies. SAE Technical Paper, No. 2001-01-0039.

Pawar, P.R. and Saraf, M.R. (2009) Measurement of road profile study its effect on vehicle durability and ride, SAE Technical Paper, No 2009-26-070.

Perera, R.W. and Kohn, S.D. (2002) Issues in pavement smoothness: A summary report, NCHRP Project, pp 20-51.

Saeger, K.M. and Ferris, J.B. (2003) Plausibility checking of road profile measurements. SAE Technical Paper, No 2003-01-0669.

SD (Silicon Designs) (2009) http://www.silicondesigns.com/pdfs/2220.pdf, accessed on 15-03-2009.

SSI (Surface System and Instruments) (2009) http://www.smoothroad.com/products/ profilograph, accessed on 22-01-2009. 